\title{
Current situation and perspective of mycotoxin research in Asia
}

\author{
Yoshizawa, T. \\ Professor Emeritus, Kagawa University \\ (1212-6 Hikami, Miki, Kagawa 761-0612, Japan)
}

\begin{abstract}
In conjunction with the international current situation about the regulation for mycotoxins in food, the natural occurrence of trichothecenes (DON and NIV) and aflatoxins in Asia is overviewed. Updated information is very limited, however, being difficult to assess the exposure of Asian populations to the mycotoxins. Comprehensive surveillances are recommended to be conducted nationwide in individual countries using adequate sampling plans and validated methods. Recent advances in molecular genetic approach for identifying Fusarium graminearum and Aspergillus flavus are also reviewed briefly.
\end{abstract}

Key words : aflatoxin, deoxynivalenol, nivalenol, exposure, Fusarium graminearum, Aspergillus flavus, Asia

\section{Introduction}

Mycotoxins currently considered most significant are aflatoxins (AF), ochratoxin A (OTA), patulin, fumonisins (FM), zearalenone (ZEN) and some trichothecenes including deoxynivalenol (DON) and T-2/HT-2 toxins. The risk assessment of FM, OTA, DON, T-2/HT-2 and $\mathrm{AFM}_{1}$ was carried out at the $56^{\text {th }}$ JECFA meeting in 2001 , and provisional tolerable daily intake values were proposed for FM, OTA, DON and T-2/HT- $2^{1 \text { ) }}$.

As for worldwide mycotoxin regulations, at least 99 countries have regulations including guidelines for food and/or feed, and the total population in these countries represents approximately $87 \%$ of the world's inhabitants ${ }^{2}$. Among 47 countries/areas in Asia, 26 countries/areas have regulations for foods and/or feeds in 2003, an increase of 86 percent (12 countries) compared to $1995^{3}$. Table 1 shows the current situation of regulations for mycotoxins in food in Asia, in comparison with the situation in 1995. As AF are toxins regulated most strictly and worldwide, all countries/districts with mycotoxin regulations in Asia have at least regulatory limits for $A F B_{1}$ or total $A F$ (the sum of aflatoxin $B_{1}, B_{2}, G_{1}$ and $G_{2}$ ) in food. Total $A F$ and $A F B_{1}$ are regulated in 18 and 13 countries, respectively, followed by $\mathrm{AFM}_{1}$, patulin, OTA, DON and ZEN in 12, 8, 5, 4 and 2 countries, respectively. Only one country has a regulation either FM or T-2.

At the moment, regulatory standards (maximum tolerated levels) set by Codex Alimentarius are $15 \mu \mathrm{g} / \mathrm{kg}$ for total AF in peanuts intended for further processing, and 0.5 $\mu \mathrm{g} / \mathrm{kg}$ for $\mathrm{AFM}_{1}$ in milk, and $50 \mu \mathrm{g} / \mathrm{kg}$ for patulin in apple juice and apple juice ingredients in other beverages. Several regulations have been harmonized between countries belonging to economic communities (EU, MERCOSUR, Australia/New Zealand).

In relation to the international current trend noted above, recent information on the 


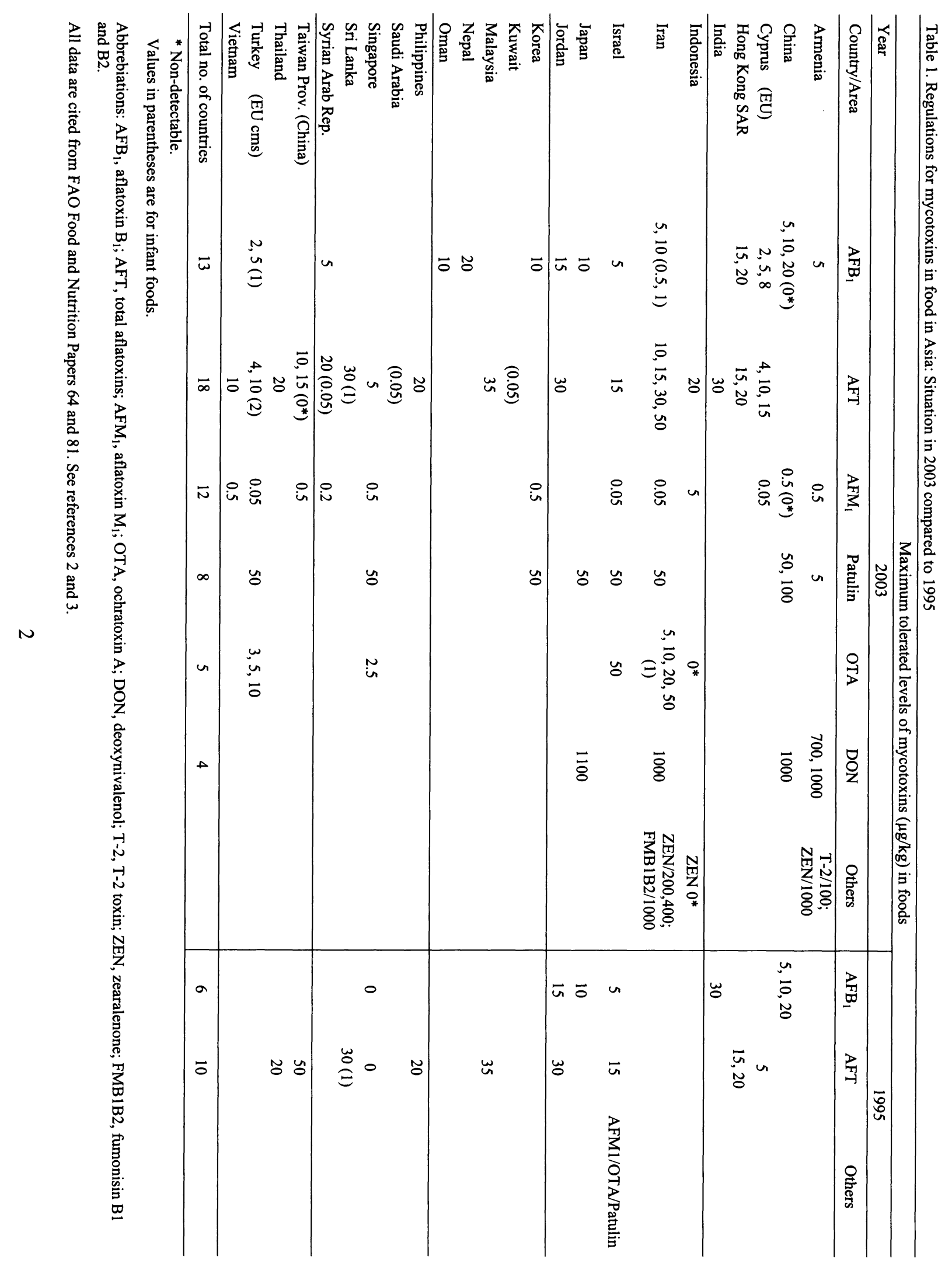


mycotoxin occurrence in Asia is briefly overviewed in this paper. However, updated information is very limited, being difficult to assess the exposure of Asian populations to mycotoxins. Comprehensive surveillances are recommended to be conducted nationwide in individual countries, using adequate sampling plans and validated analytical methods. Furthermore, the co-occurrence of multiple mycotoxins (AF, OTA, various Fusarium toxins, etc.) should be taken into account. Several research subjects required are also considered briefly.

\section{Geographical distribution of trichothecene occurrence in Asia}

Fusarium head blight (FHB) or scab is a significant fungal disease of wheat, barley and corn imposing a threat to the world's food supply. A major pathogen is the ascomycete Fusarium graminearum Scwabe (teremorph: Gibberella zeae (Schwein.) Petch), and is well-known as one of the most important producer of Fusarium mycotoxins such as DON, nivalenol (NIV) and ZEN. Distribution of DON and NIV varies by region in the world ${ }^{4}$. DON is the most widely distributed Fusarium mycotoxin and occurs worldwide in cereals of temperate regions. On the other hand, NIV has been found extensively in Japan and Korea and at relatively low levels in cereal samples from Europe, southern Africa and New Zealand, but very rarely found in North and South America.

Table 2 shows the geographical distribution of DON and NIV in wheat, barley and corn in Asia. In Japan, there is a regional difference in the occurrence of DON and NIV in domestic wheat and barley grains ${ }^{5-7)}$. The predominant toxin is DON in the northern areas (Hokkaido and Tohoku) and NIV is in the central area (Honshu), while in the western area (Shikoku and Kyushu) DON is more frequent than NIV. In Korea, a similar pattern to the central Japan was found in barley grains, but in corn samples DON is more important than $\mathrm{NIV}^{8,9)}$. In China, DON is known to be the major causative toxin responsible for almost all of the episodes of human red mold intoxication, sometimes with its acetylated derivatives, and NIV being detected in less incidence and level ${ }^{10-12}$. In addition, DON is found as a predominant trichothecene in both wheat and corn from high-incidence areas for human esophageal cancer in Henan Province ${ }^{13,14)}$ and for Kashin-Beck disease in Shaanxi and Shanxi Provinces ${ }^{15}$. NIV has been detected in corn from a southern region of China (Guanxi), the Philippines and Indonesia in far less incidence and level, rarely together with DON ${ }^{16-18)}$.

\section{Exposure assessment of trichothecenes}

Regarding the regulatory or guideline limits of trichothecenes, DON is now regulated in wheat (and/or its flour) and other cereals in 37 countries including four Asian countries; Armenia, China, Iran and $\mathrm{Japan}^{2)}$. The regulation limit ranges from 300 to $2000 \mu \mathrm{g} / \mathrm{kg}$, depending on food commodities and food types. Regulation for NIV has not yet been established, but NIV is considered to be given more attention from a regulatory point of perspective, because of its relatively higher toxicity as compared to $\mathrm{DON}^{2)}$.

Recently, a comprehensive project on the exposure of the population to Fusarium toxins has been carried out by EU member countries ${ }^{19)}$. The databases covered altogether 16 Fusarium mycotoxins and 44,959 analyses. Wheat and wheat containing products (like bread and pasta) are the predominant source for DON and NIV intake. The average level intakes of DON for entire population as well as for the group adults are low and do not exceed $46.1 \%$ of the tolerable daily intake (TDI) of $1 \mu \mathrm{g} / \mathrm{kg}$ body weight/day. However, for the group of young children the intake might come to the $\mathrm{TDI}^{20}$.

In Japan, $1.1 \mathrm{mg} / \mathrm{kg}$ of DON in wheat grain was established as a provisional regulatory 


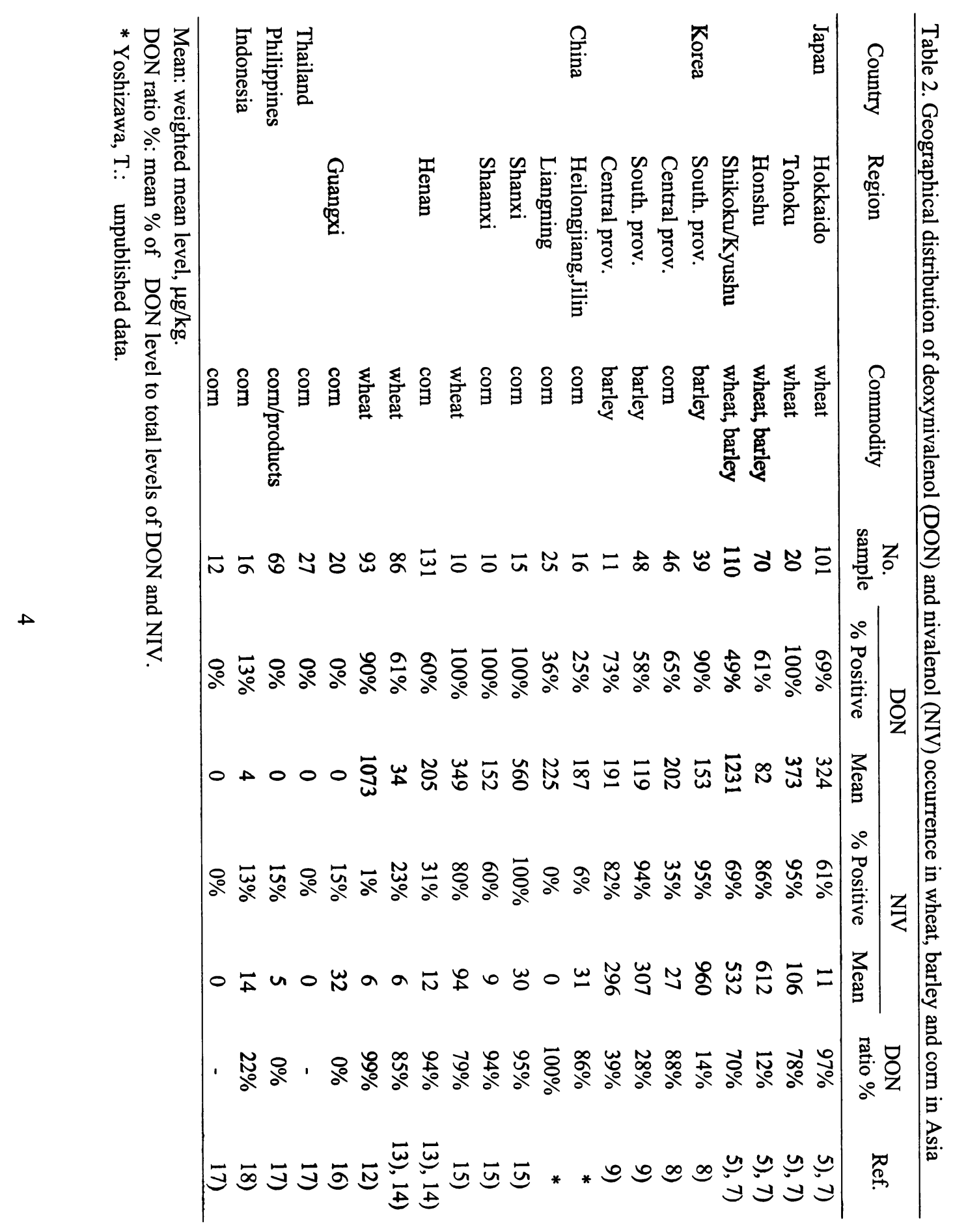


limit in 2002. According to studies on the exposure assessment of DON, the average level intakes of DON were estimated to be $3.7 \%$ and $8.3 \%$ of the TDI of DON for entire

population and children, respectively, based on average levels of DON in domestic and imported wheat grains ${ }^{21)}$. The exposure levels estimated from DON in rice were very low; $0.1 \%$ and $0.2 \%$ of TDI for adults and children, respectively ${ }^{22)}$.

Meky et al. $^{23)}$ established methodology for a candidate biomarker of human exposure to DON and tested this methodology on urine samples from a potentially highly exposed population. Urine samples were collected from female inhabitants of Linxian County, China, a high risk region for esophageal cancer and an area of potentially high DON exposure, and Gejiu, a low risk region in China. The mean levels of DON, following $\alpha$-glucuronidase treatment, from the suspected high and low exposure regions of China were $37 \mathrm{ng} / \mathrm{mL}$ (range 14-94 $\mathrm{ng} / \mathrm{mL}$ ) and $12 \mathrm{ng} / \mathrm{mL}$ (range $4-18 \mathrm{ng} / \mathrm{ml}$ ), respectively. This was estimated to correspond to daily exposures of $1.1-7.4 \mu \mathrm{g} / \mathrm{kg}$ bw/day and $0.3-1.4 \mu \mathrm{g} / \mathrm{kg}$ bw/day, respectively.

\section{Aflatoxin occurrence in Asia}

AF have been found in a variety of agricultural commodities, but the most pronounced contamination has been encountered in corn, peanuts, cottonseed, dried fruits, tree nuts and spices $^{24)}$. From the point of view of dietary intake, AF in foods used as staples such as rice, wheat and corn are considerable significance. The third joint FAO/WHO/UNEP international conference on mycotoxins (United Nations Environmental Programme) in 1999 made a series of recommendations reflecting a new perspective on the health and economic impact of mycotoxins in staple foods ${ }^{25}$. Unlike other cereals, however, reports on the actual incidence of mycotoxin in rice are limited, and the data available for rice, especially in Asia, are mostly outdated and there is no comprehensive data set that can serve as basis for assessing exposure of humans to AF due to consumption of these commodities.

Table 3 summaries updated data on AF contamination of rice in Asia ${ }^{21,26-29)}$. Sales and Yoshizawa $^{26)}$ attempted to apply an immunoaffinity column clean-up method coupled with HPLC (detection limit for AF: $25 \mathrm{ng} / \mathrm{kg}$ ) to determine an updated profile of AF contamination in rice and its byproducts from the Philippines. The total AF levels in 78 samples of polished and brown rice ranged from $<0.025-2.7 \mu \mathrm{g} / \mathrm{kg}$ (mean of positive samples: $0.37 \mu \mathrm{g} / \mathrm{kg}$ ) and 0.03-8.7 $\mu \mathrm{g} / \mathrm{kg}$ (mean of positive samples: $2.7 \mu \mathrm{g} / \mathrm{kg}$ ), respectively. The incidences ( $\%$ of positive samples) of AF in polished and brown rice were $94 \%$ and $100 \%$, respectively. The estimated potential daily intake of $\mathrm{AFB}_{1}$ from rice is between 0.1 and $7.5 \mu \mathrm{g} / \mathrm{kg} \mathrm{bw} / \mathrm{day}$, the mean of which is $1.0 \mathrm{ng}$ representing 9.1-5.3 times the estimated tolerable daily intake for $\mathrm{AFB}_{1}$ in Asia which is from $0.11-0.19 \mu \mathrm{g} / \mathrm{kg}$ bw/day, at a cancer risk level of $10^{-5}$. Results of this study are indicative of the potentially high risk of exposure of Filipinos to AF in rice.

Under a multi-centre study conducted by the Indian Council of Medical Research, 1511 samples of parboiled rive were collected from rural and urban areas of 11 states representing different geographical regions of India ${ }^{27)}$. The presence of $\mathrm{AFB}_{1}$ at levels $\geq 5 \mu \mathrm{g} / \mathrm{kg}$ was found in $38.5 \%$ of the total number of samples of the parboiled rice. About $17 \%$ of the total samples showed the presence of $\mathrm{AFB}_{1}$ above the Indian regulatory limit of $30 \mu \mathrm{g} / \mathrm{kg}$.

Park et al. ${ }^{28)}$ reported that $5 / 88(6 \%)$ of food-grade rice samples, collected in Seoul, Korea, were contaminated with $\mathrm{AFB}_{1}$ with an average of $4.8 \mu \mathrm{g} / \mathrm{kg}$. Rice was considered to be the major contributor to the dietary intake of $\mathrm{AFB}_{1}$, and it was calculated that the probable daily intake of $\mathrm{AFB}_{1}$ for Koreans exceeds the estimated provisional maximum tolerable daily intakes. 
Table 3. Updated data on aflatoxin $\mathrm{B}_{1}\left(\mathrm{AFB}_{1}\right)$ contamination of rice in Asia

\begin{tabular}{llccccc}
\hline Commodity & Country & $\begin{array}{c}\text { No. } \\
\text { samples }\end{array}$ & $\begin{array}{c}\text { Positive } \\
(\%)\end{array}$ & $\begin{array}{c}\mathrm{AFB}_{1} \text { mean } \\
(\mu \mathrm{g} / \mathrm{kg})\end{array}$ & $\begin{array}{c}\text { Method/LOD (LOQ) } \\
(\mu \mathrm{g} / \mathrm{kg})\end{array}$ & Ref. \\
\hline $\begin{array}{l}\text { Polished rice, } \\
\text { imported }\end{array}$ & Japan & 20 & $25 \%$ & $(0.1-0.3)$ & IAC-HPLC/0.1 & $29)$ \\
$\begin{array}{l}\text { Rice, food-grade } \\
\text { Brown \& polished }\end{array}$ & Korea & 88 & $6 \%$ & 4.8 & ELISA/1, HPLC/0.6 & $28)$ \\
$\begin{array}{l}\text { rice } \\
\text { Rice, imported }\end{array}$ & Philippines & 41 & $100 \%$ & 0.39 & IAC-HPLC/0.025 & $26)$ \\
$\begin{array}{l}\text { Parboiled rice } \\
\text { India }\end{array}$ & 1511 & $38.5 \%$ & $>5$ & IAC-HPLC/0.025 & $26)$ \\
& & $17 \%$ & $>30$ & & $27)$ \\
Rice, domestic & Japan & 53 & $0 \%$ & - & IAC-HPLC/0.1 & $21)$ \\
\hline
\end{tabular}

Abbrebiations: LOD, limit of detection; LOQ, limit of quantitation; IAC, immunoaffinity column; HPLC, high-performance liquid chromatography; ELISA, enzyme-linked immunosorbent assay.

\section{Current taxonomical aspect for $\boldsymbol{F}$. graminearum}

Molecular phylogenetic analyses based on eleven nuclear genes at six loci revealed that $F$. graminearum consists of at least nine biogeoraphically structured lineages ${ }^{30,31)}$. Among nine lineages of the species, now named as $F$. graminearum-complex $(=F$. graminearum Group 2) according to the new concept, $F$. graminearum Schwabe s, str. (lineage 7) and $F$. asiaticum $\mathrm{O}^{\prime}$ Donell et al. (lineage 6 ) are most significant pathogens in wheat, barley and corn in Asia $^{32)}$. There is a geographical difference in the distribution of these lineages in Asian countries $^{34)}$. For example, $F$. asiaticum is predominant in Chinese wheat, whereas $F$. graminearum is the most predominant followed by $F$. boothii (linkage 3 ) and $F$. asiaticum in Korean corn. In Japanese wheat and barley, lineage 6 is predominant in western to central regions, while lineage 7 is in northeastern to northern regions. As for trichothecene production of these lineages isolated from Japanese cereals, $F$. graminearum (lineage 7 ) produced DON, which is subdivided into 3A-DON- (about $70 \%$ ) and 15A-DON-producer (about $30 \%$ ), and $F$. asiaticum (lineage 6) produced either NIV (about $70 \%$ of isolates) or 3A-DON (about $30 \%$, 15A-DON producer was below $1 \%)^{33)}$

\section{Molecular genetic approach for identifying aflatoxigenic fungi}

A. flavus and $A$. paratisicus are responsible for the overwhelming proportion of AF found in foodstuffs throughout the world. A. flavus produces only B-type AF and sometimes the mycotoxin cyclopiazonic acid (CPA), while $A$. paratisicus produces both B- and G-type AF, but never CPA. Several other Aspergillus species are now known to produce AF but they are of little practical importance in foods.

Recent advances in molecular technology have enabled the rapid detection and identification of filamentous fungi. Heteroduplex analysis allows genetic screening of unknown DNA fragments in a sequence-dependent manner ${ }^{34,35)}$. For identification of Aspergillus section Flavi species, Kumeda et al. ${ }^{36,37)}$ developed a new PCR-based method for heteroduplex panel analysis (HPA), which was highly reproducible and proved to be a powerful tool for classifying Aspergilli isolates without morphological observation of 
phenotypic characteristics. Based on the HPA results, 19 HPA types were identified from a total of 351 examined Aspergillus section Flavi isolates ${ }^{38)}$. These HPA types includes 6 types (F-1 to F-6 for $A$. flavus/A. oryzae), 2 type (P-1 and $\mathrm{P} 2$ for $A$. parasiticus), 5 types (N-1 to N-5 for $A$. nomius). As for $A$. flavus/A. oryzae, type F-1 and F-2 are dominant.

Sales $^{39)}$ applied HPA analysis for identification and differentiation of Aspergillus section Flavi isolates from different agricultural commodities from the Philippines, indicating eight genotypes with distinct HPA genotypes, with $A$. flavus $\mathrm{F}-1$ and $A$. parasiticus $\mathrm{P}-1$ as the most common genotypes. Furthermore, aside from the previously reported HPA genotypes, five additional Aspergillus section Flavi genotypes were identified. This strongly indicates a broader diversity of this group in the Southeast Asian region.

\section{Conclusion and recommendation}

In general, updated information on mycotoxin contamination in Asia is insufficient, being difficult to assess the exposure of Asian populations to mycotoxins. Comprehensive surveillances are recommended to be conducted nationwide in individual countries, using adequate sampling plans and validated analytical methods. In addition, more emphasis should be placed on total diet and duplicate studies rather than individual foods.

Collaborative and partnership researches between scientists and laboratories in Asian countries should be encouraged to assess the extent of human exposure to mycotoxins in this region. In addition, Asian countries are urged to supply FAO and WHO with all available data on levels of exposure and related effects determined experimentally, clinically, or epidemiologically.

Recent progresses in molecular technology have introduced new concepts in the taxonomy of mycotoxigenic fungi including $F$. graminearum-complex and Aspergillus section Flavi. Further studies based on molecular genetic approaches are encouraged to elucidate a broader diversity of the fungi in Asian region.

\section{Acknowledgements}

The author is grateful to the following co-workers who visited the author's laboratory from Asian countries, for supporting some parts of this study: Yin-Won Lee (Korea), Jin-Cheol Kim (Korea), Xue-Yun Luo (China),Yi Luo (China), Yin-Zhe Jin (China), Hong-Ping Gao (China), Feng-Qin Li (China), Maitree Suttajit (Thailand), Warunee Varanyanond (Thailand), Pairojana Luangpitsuksa (Thailand), Nantari Chokethaworn (Thailand), Suwiwek Lipigorngoson (Thailand), Chawalert Trikarunasawat (Thailand), Norhayati Ali (Malaysia), Noor Hasani Hashim (Malaysia), Rosario H. Arim (Philippines), Aida R. Aguinaldo (Philippines), Priscilla C. Sanchez (Philippines), Erlinda I. Dizon (Philippines), Anthony C. Sales (Philippines), Sarjono (Indonesia)

\section{References}

1) World Health Organization (WHO), Safety Evaluation of Certain Mycotoxins in Food (WHO Food Additives Series 47), World Health Organization, Geneva, (2001).

2) Food and Agriculture Organization of the United Nations (FAO): Worldwide regulations for mycotoxins food and feed in 2003. FAO Food and Nutrition Paper 81, Rome, Italy, (2004).

3) Food and Agriculture Organization of the United Nations (FAO): Worldwide regulations for Mycotoxins 1995. A compendium. FAO Food and Nutrition Paper 64. Rome, Italy, (1997). 
4) International Agency for Research on Cancer (IARC): IARC Monographs on the Evaluation of Carcinogenic Risks to Humans, Vol. 56, Some Naturally Occurring Substances: Food Items and Constituents, Heterocyclic Aromatic Amines and Mycotoxins, pp. 245-3951, (1993).

5) Jin, Y. Z.: Ph. D. dissertation, The United Graduate School of Agricultural Sciences, Ehime University, Ehime, Japan, (1995).

6) Yoshizawa, T., Jin, Y.Z.: Food Add. Contam., 12, 689-694 (1995)

7) Yoshizawa, T., Jin, Y Z.: Mycotoxins, 47, 15-18 (1998)

8) Kim, J.C., Kang, H.J., Lee, D.H., Lee, Y.W., Yoshizawa, T.: Appl. Environ. Microbiol., 59, 3798-3802 (1993)

9) Lee, Y. W., Kim, J.C., Lee, D.H., Kang, H.J., Yoshizawa, T.: J. Food Hyg. Soc. Japan, 36, 85-88 (1995)

10) Luo, X.Y.: Proceedings of the Second Asian Conference on Food Safety, Bangkok, pp. 129-136 (1994)

11) Li, F.Q., Luo, X.Y., Yoshizawa, T.: Natural Toxins, 7, 93-97 (1999)

12) Li, F.Q., Li, Y.W., Luo, X.Y., Yoshizawa, T.: Food Add. Contam., 19, 163-167 (2002)

13) Luo, Y., Yoshizawa, T., Katayama, K.: Appl. Environ. Microbiol., 56, 3723-3726 (1990)

14) Gao, H.P., Yoshizawa, T.: Mycotoxins, 45, $51-55$ (1997)

15) Luo, Y., Yoshizawa, T., Yang, J.S., Zhang, S.Y., Zhang, B.J.: Mycotoxin Res., 8, 85-91 (1992)

16) Li, F.Q., Yoshizawa, T., Kawamura, O., Luo, X.Y., Li, Y.W.: J. Agric. Food Chem., 49, 4122-4126 (2001)

17) Yamashita, A., Yoshizawa, T., Aiura, Y., Sanchez, P.C., Dizon, E.I., Arim, R.H., Sardjono: Biosci. Biotech. Biochem., 59, 1804-1807 (1995)

18) Ali, N., Sardjono, Yamashita, A., Yoshizawa, T.: Food Add. Contam., 15, 377-384 (1997)

19) Scientific Commission, Reports on tasks for scientific cooperation. Task 3.2.10 Collection of occurrence data of Fusarium toxins in food and assessment of dietary intake by the EU Member State. Directorate-General Health and Consumer Protection, Office for Official Publication of the European Committees, Luxembourg, 2003.

20) Scientific Committee on Food, European Committee (2002), Opinion of the Scientific Committee on Food on Fusarium toxins Part 6: Group of T-2 toxin, HT-2 toxin, nivalenol and deoxynivalenol (SCF/CS/CNTM/MYC/27 Final). Brussel.

21) Sugita-Konishi, Y., Nakajima, M., Tabata, S., Ishikuro, E., Tanaka, T., Norizuki, H., Itoh, Y., Aoyama, K., Fujita, K., Kai, S., Kumagai, S.: J. Food Prot., 69, 1365-1370 (2006)

22) Tanaka, T., Yoshizawa, T., Tanaka, H., Sugiura, T., Takatori, K., Kumagai, S.: New horizon of mycotoxicology for assuring food safety eds. Yoshizawa, T., Kumagai, S., Goto, T.), pp. 83-88 (2004), Japanese Association of Mycotoxicology, Tokyo, Japan.

23) Meky, F.A., Turner, P. C., Ashcroft, A.E., Miller, J.D., Qiao, Y.L., Roth, M.J., Wild, C.P.: Food Chem. Toxicol., 41, 265-273 (2003)

24) International Agency for Research on Cancer (IARC): IARC Monograph on the Evaluation of the Carcinogenic Risk of Chemicals to Humans, Vol. 82, Traditional Herbal Medicines, Some Mycotoxins, Naphthalene and Styrene, (2002), IARC Press, Lion, France.

25) Third Joint FAO/WHO/UNEP International Conference on Mycotoxins, (3-6 March, 1999), Tunis, Tunisia [http://www.fao.org/ag/agn/food/pdf/mycotoxins_report_en.pdf]

26) Sales, A.C., Yoshizawa, T.: Food Add. Contam., 22, 429-436 (2005)

27) Toteja, G.S., Mukherjee, A., Diwakar, S., Padam, S., Saxena, B.N., Sinha, K.K., Sinha, A.K., Kumar, N., Nagaraja, K.V., Girija Bai, K., Prasad, C.A., Vanchinathan, S., Rajat, R., Sarkar, S.: Food Add. Contam., 23, 411-414 (2006) 
28) Park, J.W., Kim, E.K., Kim, Y.B.: Food Add. Contam., 21, 70-75 (2004)

29) Lipigorngoson, S., Ali, N., Yoshizawa, T.: Mycotoxins, 53, 95-101 (2003)

30) O’Donnell, K., Kistler, H. C., Tacke, B.K., Casper, H.H.: Proc. Natl. Acad. Sci. USA, 97, 7905-7910 (2000)

31) Ward, T.J., Bielawski, J.P., Kistler, H.C., Sullivan, E., O’Donnell, K.: Proc. Natl. Acad. Sci. USA, 99, 9278-9283 (2002)

32) Aoki, T.: Mycotoxins, 55, 55-63 (2005)

33) Suga, H.: Mycotoxins, 55, 65-71 (2005)

34) Delwart, E. L., Shpaer, E. G., Louwagie, J., McCutchan, F. E., Grez, M., Rubsamen-Waigmann, H., Mullins, J.J.: Science, 262, 1257-1261 (1993)

35) Ganguly, A., Rock, M.J., Prockop, D.J.: Proc. Natl. Acad. Sci. USA, 90, 10325-10329 (1993)

36) Kumeda, Y., Asao, T.: Appl. Environ. Microbiol., 67,4084-4090 (2001)

37) Kumeda, Y., Asao, T., Takahashi, H., Ichinoe, M.: FEMS Microbiol. Ecol., 45, 229-238 (2003)

38) Kumeda, Y.: Mycotoxins, 56, 77-84 (2006)

39) Sales, A. T.: Ph. D. dissertation, The United Graduate School of Agricultural Sciences, Ehime University, Ehime, Japan, (2006). 